\title{
Scuttle flies (Diptera: Phoridae) of saline habitats of the Gulf of Gdańsk, Poland
}

\author{
Ewa Durska, Elżbieta Kaczorowska \& R. Henry L. Disney
}

Durska, E., Kaczorowska, E. \& Disney, R. H. L. 2005: Scuttle flies (Diptera: Phoridae) of saline habitats of the Gulf of Gdańsk, Poland. — Entomol. Fennica 16: $159-164$.

Results of a survey of the scuttle flies (Diptera: Phoridae) of saline habitats of the Gulf of Gdańsk are reported. Within three study seasons (1999-2001), at ten localities representing coastal brackish and maritime habitats, 39 phorid species were collected. Among these, 36 were new to these areas, and Xenotriphleba dentistylata Buck was the first record for Poland. The dominance structure, phenology and abundance of phorids of saline habitats are described.

E. Durska, Museum and Institute of Zoology, PAS, Wilcza 64, 00-679 Warszawa, Poland; E-mail:edurska@miiz.waw.pl

E. Kaczorowska, Department of Invertebrate Zoology, University of Gdańsk, Pitsudskiego 46,81-378Gdynia,Poland; E-mail: saline@sat.ocean.univ.gda.pl R. H. L. Disney, University Museum of Zoology, Cambridge CB2 3EJ, United Kingdom;E-mail: rhld2@cam.ac.uk

Received 23 October 2002, accepted 9 November 2004

\section{Introduction}

Scuttle flies (Phoridae) are one of the most abundant families of Diptera and "the prime candidate for being the most biologically diverse family of insects on the planet" (Disney 1990, 1994). Onequarter of the ca. 3,000 species described occur in the Palaearctic Region.

The seashore is generally not regarded as a suitable habitat for Phoridae, but the larvae of some New World species of Megaselia are known to be intertidal and thus able to cope with fluctuations in salinity (Saunders 1928, Cheng \& Hogue 1974). Disney (2002) reported that the European Megaselia yatesi lives within the voids of the first shingle ridge above high watermark and that its larvae are likely to be subjected to a range of salinities following the fluctuations of the tides and rainfall. Its eggs, being in a constantly high humidity, are atypically thin-walled, seemingly because they are not exposed to the risk of desiccation. Records of scuttle flies in maritime habitats are otherwise sparse, apart from scattered records and reports, such as phorids and other Diptera trapped in the oil oozing from a dead whale (Cobert \& Disney 1998). Maritime habitats have not been systematically sampled for Phoridae.

In Poland, little is known about scuttle flies of saline habitats. Szadziewski (1983), investigating Diptera of these areas, found only eight phorid species. All of these were haloxenes i.e. species that occur and develop numerously more often in specific non-saline than in saline habitats. In this paper, we report on the phorids of the beaches and coastal brackish areas of the Gulf of Gdańsk. 


\section{Material and methods}

\subsection{Study area}

Material was collected on ten areas, representing two types of habitat bordering the Baltic Sea-the coastal brackish and marine habitats. The first area was at the Bay of Puck and Gdańsk-Górki Wschodnie, and the second one was formed by the eight beaches adjacent to the Gulf of Gdańsk.

The brackish area, viz. Gdańsk-Górki Wschodnie (the coastal type), is situated at the mouth of the Wisła Śmiała river. The saline area beside the river comprises bulrushes, brackish marshes and brackish meadows. The latter are overgrown by halophytes such as Aster tripolium, Triglochin maritimum, Glaux maritima, and Artriplex hastatum var. salinarium. On the stony dam, Aster tripolium, Atriplex hastatum, Spergularia salina, Elymus arenarius, Solanum dulcamara and Sonchus arvensis can be found. Stones in the river bottom and flooded parts of the dam - where material was also collected - are covered with algae Enteromopha sp. and Cladophora sp.

The flies of the Bay of Puck were caught over coastal waters, and in brackish marshes and meadows along the waterside. The bay banks are covered with Phragmites communis, whereas on the meadows occur Triglochin maritimum, Atriplex hastatum var. salinum, Aster tripolium, Glaux maritima and Spergularia salina (Szadziewski 1983).

The fFlies were collected in supralittoral and epilittoral zones of the eight beaches situated near Gdynia - Wzgórze Świętego Maksymiliana (Gdynia-Wzgórze), Gdynia - Orłowo (UTM: CF44), Sopot, Gdańsk - Jelitkowo, Gdańsk Brzeźno (UTM: CF43), Gdańsk - Górki Wschodnie (UTM: CF52), Władysławowo (UTM: CF37) and Ustka (UTM: XA25). These areas are flat and sandy, and only the locality near GdyniaOrłowo, adjacent to the cliffs, is a little stony.

\subsection{Phorid sampling, and statistical methods}

Phorids were collected from the begining of May to the end of September in 1999 and from the beginning of April to mid October in 2000 and
2001, 1-2 times a week. Flies were collected by sweeping (using an entomological net) over water's surface, algae washed ashore, soils, plants overgrowing dunes and cliffs, and in halophyte communities growing near the saline-water reservoirs. All scuttle flies were preserved in $75 \%$ alcohol. Megaselia females were not identified to species.

To describe the dominance structure of communities, a dominance index $(D)$ was used (Durska 2001):

$D=n / N^{*} 100 \%$

where $n=$ the abundance of a given species, and $N=$ the accumulated abundance of all phorid species.

The dominance index $(D)$ was used to classify the species into four classes: (1) eudominant (over $15.0 \%$ ), (2) dominant (from $5.1 \%$ to $15.0 \%$ ), (3) subdominant (from $1.1 \%$ to $5.0 \%$ ) and (4) accessory species (up to $1.0 \%$ ).

\section{Results}

The material contained 230 phorid imagines. The phorid fauna of the saline habitats sampled proved to be richer ( 39 species belong to 11 genera) than expected, in view of the limited collecting by means of netting only. The most abundant genus Megaselia was represented by 21 species (only males, ca. $60 \%$ of the total catch) (Table 1 ).

\subsection{Dominance structure}

The cumulative abundance of the three eudominant ( $M$. subnudipennis, $M$. ignobilis, $M$. pulicaria complex) and one dominant species $(M$. brevicostalis) exceeded $60 \%$ of the total catch. The subdominants were represented by nine species (Fig. 1). Among the species of the lowest abundance, one male of Xenotriphleba dentistylata (Buck, 1997) was collected in $27^{\text {th }}$ of May, on the beach near Gdynia-Brzezno. It is the first record for Poland. 
Table 1. Species composition, abundance and phenology of Phoridae in saline habitats of the Gulf of Gdańsk (1999-2001). * = species new to the Polish fauna

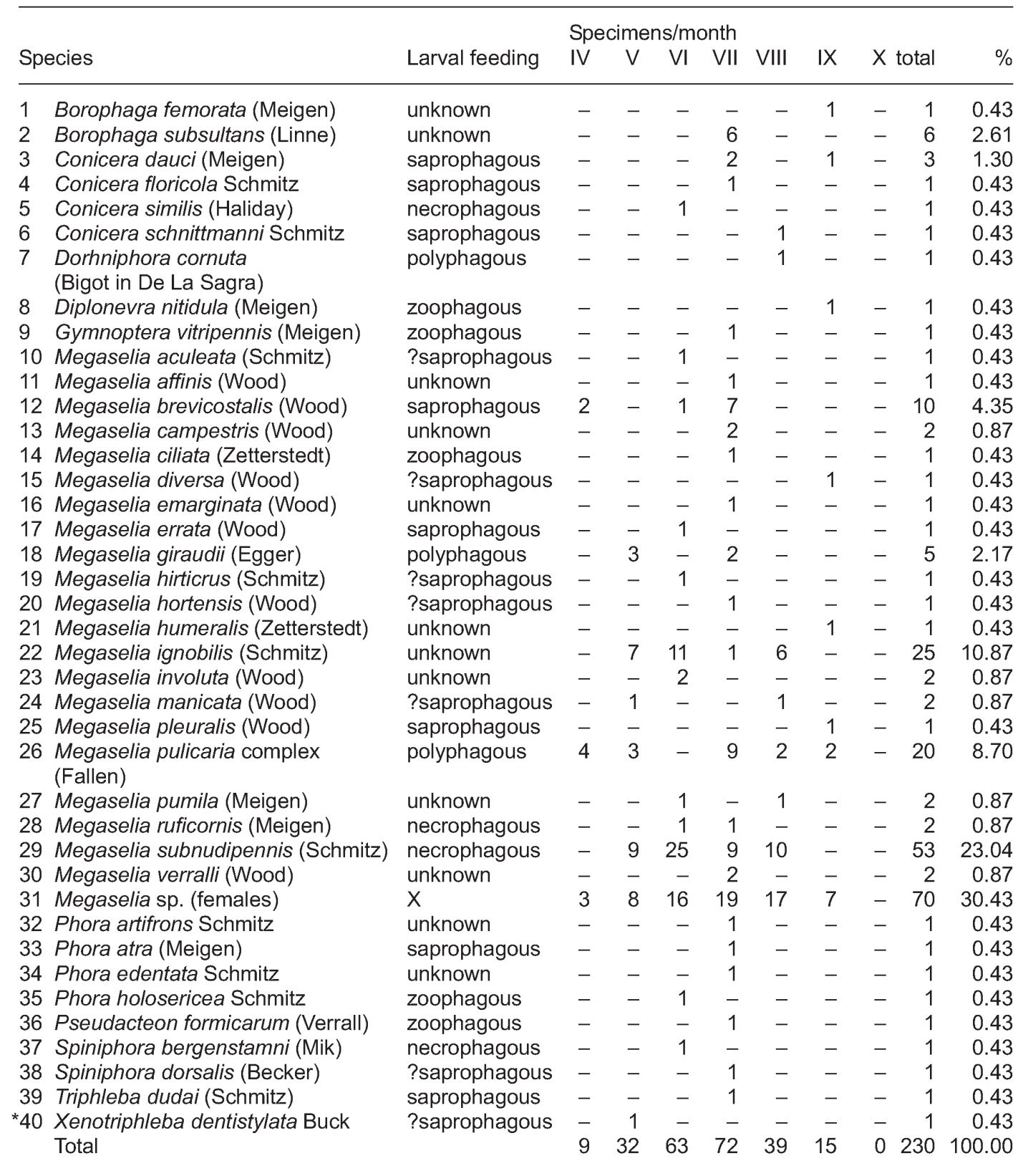

\subsection{Phenology}

During the study, the highest number of species and specimens were observed in July and also in June, and the lowest number in April and September. In October no phorids were collected (Fig.
2). The first individuals of Megaselia subnudipennis ( $23 \%$ of the total catch) and $M$. ignobilis $(10.9 \%)$ were recorded in May. The abundance peaks of these two species occured in June. M. pulicaria - complex $(8.7 \%)$ and $M$. brevicostalis $(4.4 \%)$ had their abundance peaks in 

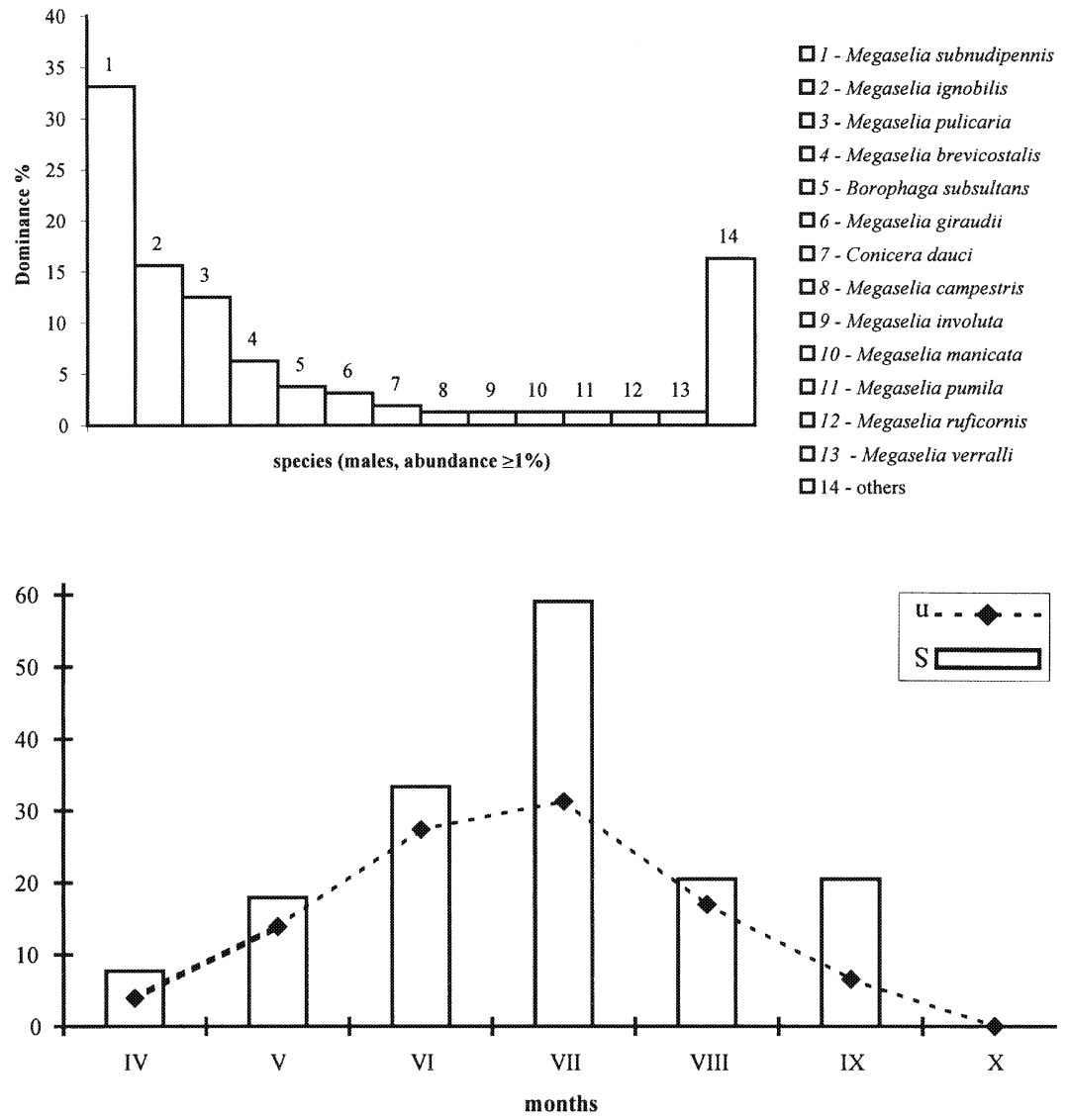

Fig. 1. The dominance structure of the phorid communities in saline habitats of the Gulf of Gdańsk.
Fig. 2. Seasonal changes in the number of phorid species (S) and relative phorid abundance $(n)$ in saline habitats of the Gulf of Gdańsk.
July. Their first individuals were collected in April.

The phenology of these four most common Megaselia species were characterised by one abundance peak during the summer (June-July).

\subsection{Species richness and abundance, and trophic groups}

The highest number of phorid species were recorded on beaches situated near GdyniaWzgórze (over $56 \%$ of the species recorded) and Władysławowo (over 35\% of species) (Fig. 3).

The highest abundance of scuttle flies was recorded for the beaches in Gdynia-Wzgórze (over $42 \%$ of the total numbers of specimens) and Gdańsk-Brzeźno (over 29\%) (Fig. 3). The latter locality is a typical sandy beach, with dunes. In Gdańsk-Brzeźno, the most numerous species was necrophagous Megaselia subnudipennis (ca.
64\%), but in Gdynia-Wzgórze M. ignobilis (ca. $21 \%$ ) dominated. In Gdańsk-Górki Wschodnie no phorids were collected.

The saprophagous and necrophagous phorids (over $50 \%$ ) were the most abundant group of species with known larval diets. (Fig. 4). Their abundance peaks fell in the summer (June-July) when most organic matter (mostly algae and fishes) was washed ashore (Table 1).

Four Megaselia species $M$. diversa, $M$. hirticrus, $M$. pleuralis and M. pumila were recorded on the meadows and swamps of the Gulf of Puck (salinity ca 7.4\%). These species were not observed in the other investigated habitats.

\section{Discussion}

Szadziewski (1983) during his investigation of saline flies in different habitats of Poland found infrequent phorid species: Aenigmatias lubbockii 
Fig. 3. Comparison of the number of species (S) and abundance ( $n$ ) of Phoridae in saline habitats of the Gulf of Gdańsk.
Fig. 4. Comparison of the number of species (S) and abundance (n) of Phoridae of different trophic groups in saline habitats of the Gulf of Gdańsk.
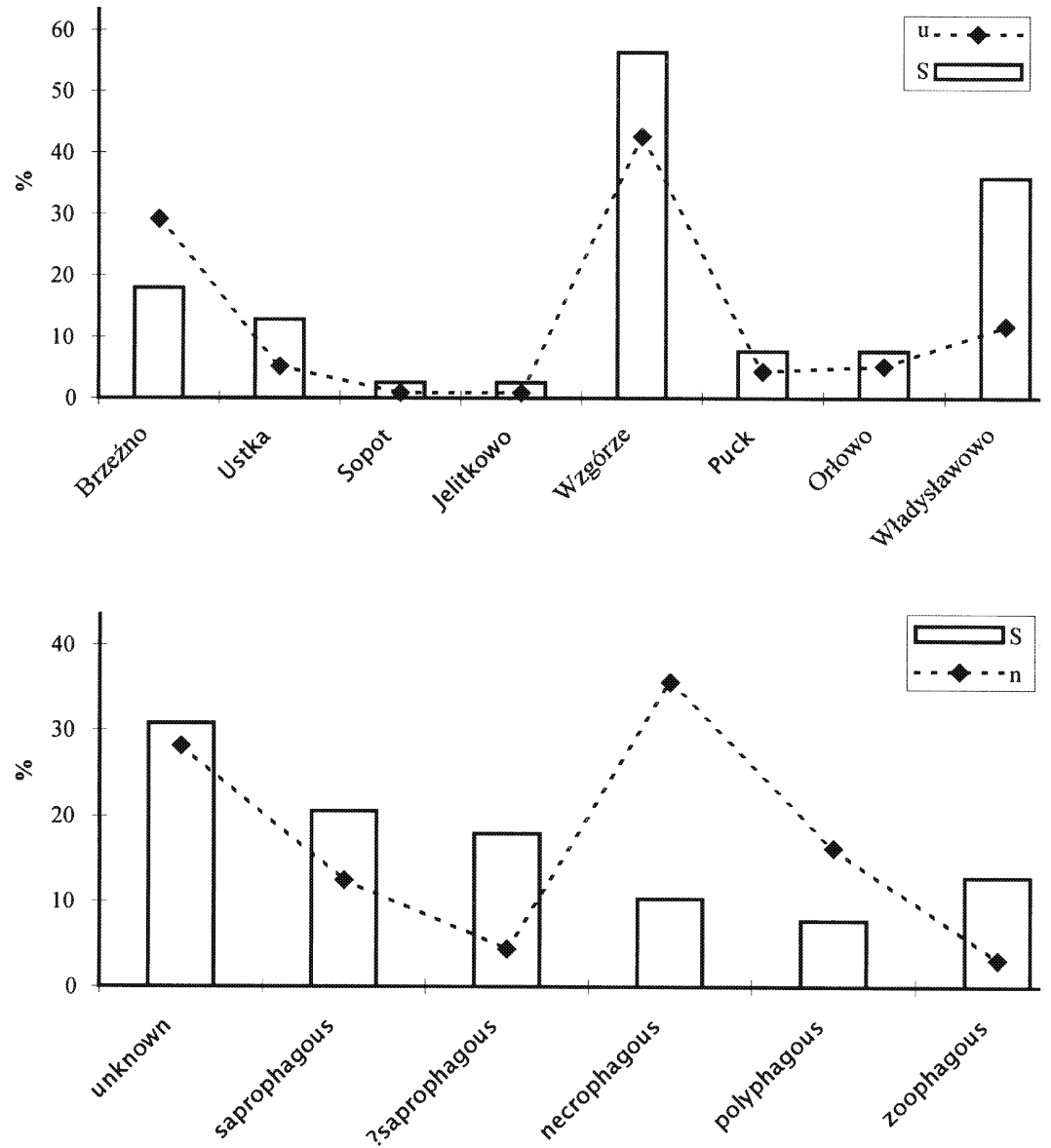

(Verrall), Megaselia brevicostalis (Wood), $M$. minuta (Aldrich), M. pumila (Meigen), M. stigmatica (Schmitz), M. unguicularis (Wood), Pseudacteon formicarum (Verrall) and P. lundbecki Schmitz. Szadziewski (1983) caught no phorids in marine habitats. However, in brackish area of the coastal type, Szadziewski collected six of the above-mentioned species: in GdańskGórki Wschodnie, he collected M. pumila, $M$. stigmatica, $M$. unguicularis, $P$. formicarum and $P$. lundbecki, and M. brevicostalis on the locality adjacent to the Gulf of Puck. In our study, only three of these species were found, viz. $M$. brevicostalis and $P$. formicarum on the beaches, but $M$. pumila was found near the Gulf of Puck. The lack of phorids in Gdańsk-Górki Wschodnie was related to the few samples caught on this locality.

Neither the authors nor Szadziewski (1983) found the truly halophilic species. All of the species found in saline areas are known to occupy other habitats, and the most of them are considered as members of the soil-borne insect fauna (Buck 1994, Weber \& Schiegg 2001). Saprophagous and necrophagous species dominate especially open sites such as open woodlands (pine plantations) and agricultural habitats (Prescher 1992, Disney 1994, Buck 1997, Durska 2001, 2002).

In the costal brackish habitats near Puck, we caught only 11 phorid individuals ( $M$. diversa, $M$. hirticrus, M. pleuralis, M. pumila and Megaselia spp. females). Of these, $M$. diversa and $M$. pleuralis have previously been recorded by Corbet \& Disney (1998) among Diptera trapped in the oil oozing from a dead whale.

The scuttle flies with saprophagous and/or necrophagous larvae, reported from saline habi- 
tats, belong to the most abundant trophic group. However, phorid fauna is more numerous in other maritime habitats. The beaches adjacent to the Gulf of Gdańsk are rather polluted and have abundant organic matter, such as decaying animals and washed-ashore algae, that attract saprophagous flies.

In another study, among 51 families of Diptera of saline habitats of the Gulf of Gdansk, the abundance of the scuttle flies made up $0.75 \%$ of the total catch (14 sampling positions; E. Kaczorowska, unpubl. data). The most abundant taxa were Chironomidae (ca. 28\%), Ephydridae (ca. $20 \%$ ) and Chloropidae (ca. 14\%). Phorids, with the majority being saprophagous and necrophagous species, peaked in July, when they represented almost $30 \%$ of the Diptera.

Acknowledgements. We thank Dr Matthias Buck for his comments on earlier version of the manuscript.

\section{References}

Buck, M. 1994: Sphaeroceridae and Phoridae (Diptera) collected by emergence traps from various terrestial habitats in southern Germany. - Studia Dipterologica 1: 93-106.

Buck, M. 1997: Untersuchungen zur Ökologischen Einnischung Saprophager Dipteren unter besonderer Berücksichtigung der Phoridae und Sphaeroceridae (Brachycera/Cyclorrhapha). — Ph.D. thesis, Universität Ulm.
Buck, M. 1997: A new genus and species of Phoridae (Diptera) from Central Europe with remarkably primitive male ganitalia. — Ent. Scand. 28: 351-359.

Cheng, L. \& Hogue, C. L. 1974: New distribution and habitat records of biting midges and mangrove flies from the coasts of southern Baja California, Mexico (Diptera: Ceratopogonidae, Culicidae, Chironomidae and Phoridae). - Ent. News 85: 211-218.

Corbet, S. A. \& Disney, R. H. L. 1998: Diptera trapped in the oil oozing from a dead whale. - Entomologist's Mon. Mag. 134: 344.

Disney, R. H. L. 1990: Some myths and the reality of scuttle fly biology. - Antenna 14: 6467.

Disney, R. H. L. 1994: Scuttle flies: The Phoridae. Chapman \& Hall, London. 467 pp.

Disney, R. H. L. 2002: A new species of maritime scuttle fly (Dipt., Phoridae) from East Sussex, England. Entomologist's Mon. Mag. 138: 19-22.

Durska, E. 2001: Secondary succession of scuttle fly (Diptera: Phoridae) communities in moist pine forest in Białowieża Forest. — Fragm. Faun. 44: 81-130

Durska, E. 2002: The phenology of dominant scuttle-fly (Diptera: Phoridae) species in the Bialowieza Forest. - Entomol. Fennica 13: 123-127.

Prescher, S. 1992: Ökologie und Biologie der Diptera, insbesondere der Brachycera, eines Klärschlammgedüngten Ackerbodens. — Ph.D. thesis, Universität Carolo-Wilhelmina zu Braunschweig.

Saunders, E. 1928: Some marine insects of the Pacific coast of Canada. - Ann. Ent. Soc. Am. 21:521-545.

Szadziewski, R. 1983: Flies (Diptera) of the saline habitats of Poland. - Pol. Pismo Entomol. 53: 31-76.

Weber, G. \& Schiegg, K. 2001: Scuttle flies (Diptera: Phiridae) from the forest reserve Sihlwald ZH. Studia Dipterologica 8: 271-276. 